\title{
Rescue therapy with stent retrievers for thromboembolism during endovascular treatment of intracranial aneurysms
}

\author{
Terapia de resgate com stent para tromboembolismo durante tratamento endovascular de \\ aneurismas intracranianos
}

Zeferino Demartini Junior', Luana A. Maranha Gatto', Gelson Luis Koppe', Tatiana F. von Hertwig de Oliveira' ${ }^{1}$ Alexandre Novicki Francisco'

\begin{abstract}
Thromboembolism is the most frequent complication in endovascular treatment of intracranial aneurysms, causing disability and death. As stent retrievers have achieved high rates of arterial recanalization in the management of ischemic stroke, these devices were tested as rescue therapy of thromboembolism during aneurysm embolization. We retrospectively analyzed 10 consecutive patients with transprocedural arterial occlusion, treated with mechanical thrombectomy at a single center. Good angiographic recanalization was achieved in eight cases, $\mathrm{mTICl} 3,2 \mathrm{~b}$ and $2 \mathrm{a}$ in five, three and two patients, respectively, without additional complications or any deaths. Five patients showed complete recovery (mRS 0) and all patients showed improvement of disability (average mRS 1.1) over a mean follow-up period of 31 months. Eight patients had good clinical recovery, while two remained with deficits (mRS 3 and 4). The study found that the stent retriever is a valuable, rapid and effective tool for restoring blood flow, improving the safety of endovascular treatment.
\end{abstract}

Keywords: intracranial aneurysms; intraoperative complications; thromboembolism; endovascular procedure; stent.

\section{RESUMO}

Tromboembolismo é a complicação mais frequente no tratamento endovascular de aneurismas cerebrais, podendo causar morte ou sequelas. Como os stent retrievers alcançaram altas taxas de recanalização arterial no tratamento do acidente vascular encefálico isquêmico, testamos esses dispositivos para tratar eventos tromboembólicos ocorridos durante a embolização de aneurismas. Foram analisados retrospectivamente 10 pacientes apresentando oclusão arterial transoperatória, tratados com trombectomia mecânica em um único centro. Obtivemos recanalização angiográfica em oito casos, mTICl 3, 2b e 2a em cinco, três e dois pacientes, respectivamente, sem complicações adicionais ou óbito. Cinco casos apresentaram recuperação completa (mRS 0) e todos os pacientes apresentaram melhora dos déficits (mRS médio 1.1) durante acompanhamento médio de 31 meses. Oito pacientes apresentaram boa recuperação clínica, enquanto dois permaneceram com déficits (mRS 3 e 4). 0 estudo concluiu que stents são uma ferramenta valiosa, rápida e eficaz para restaurar o fluxo sanguíneo, aumentando a segurança do tratamento endovascular.

Palavras-chave: aneurisma intracraniano; complicações intraoperatórias; tromboembolia; procedimentos endovasculares; stents.

Endovascular treatment of intracranial aneurysms is a minimally invasive approach to occlude an aneurysm and prevent hemorrhage, and its acceptance has progressively increased since FDA approval in $1995^{1,2}$. The most frequent complication, and the main cause of disability or death, is thromboembolic occlusion ${ }^{3}$, which occurs in $0.96 \%$ to $12.5 \%$ of these patients ${ }^{1,2,4,5}$. Timely recanalization is effective in the management of thromboembolism and, currently, it is done by intra-arterial or intravenous delivery of fibrinolytic or antiplatelet agents ${ }^{6-9}$. Since the development of the stent retriever technique, high quality evidence about the efficacy of mechanical thrombectomy has become available, justifying changes in the current therapy ${ }^{10}$. Nevertheless, the use of a stent beyond a coil mass is still not validated, nor is the rate of aneurysm perforation by the device. We present a small series of transprocedural intracranial vessel occlusion managed with the stent retriever to achieve a good recanalization rate.

Pontifícia Universidade Católica do Paraná, Departamento de Neurocirurgia, Curitiba PR, Brasil;

Correspondence: Zeferino Demartini Junior; Hospital Universitario Cajuru - PUCPR, Departamento de Neurocirurgia; Avenida São José, 300 ; 80050 -350 Curitiba PR, Brasil; E-mail: demartiniz@gmail.com

Conflict of interest: There is no conflict of interest to declare.

Received 29 October 2017, Received in final form 18 December 2017, Accepted 24 January 2018. 


\section{METHODS}

During the period from October 2010 to November 2016, a total of 543 aneurysms were treated by endovascular procedures at a single institution. Ten consecutive patients with diagnoses of thromboembolic occlusion of a major cerebral artery underwent rescue therapy using a stent retriever. There were no exclusion criteria for the procedure or selection of the best candidates.

Endovascular treatment of the aneurysms was performed under general anesthesia in all cases. Transfemoral diagnostic angiography was performed right before the procedure using a low-osmolar nonionic contrast agent (Omnipaque, Nycomed, Oslo, Norway). Initial intravenous boluses of 5000 IU of heparin were infused when starting the angiography, followed by $1000 \mathrm{IU}$ at each hour of the procedure. A $6 \mathrm{~F}$ guide catheter (Chaperon, Microvention, Inc, Tustin, CA, USA; or Neuron, Penumbra, Inc., Alameda, CA, USA) was placed in the internal carotid or vertebral artery. Continuous flushing through catheters was maintained by infusion of $1000 \mathrm{IU}$ heparin per 1-L sodium chloride solution. Aneurysms were embolized through a microcatheter (Echelon" - 10, ev3 Neurovascular, Irvine, CA, USA) over a guidewire (SilverSpeed" - 10, ev3), using mechanical detachable coils (Axium 3D or Helix, ev3) until angiographic complete obliteration. Two procedures employed balloon remodeling (HyperForm 4x7, ev3), and two employed stent assistance (Solitaire $4 \times 15 \mathrm{~mm}$ or $4 \times 20 \mathrm{~mm}$, ev3).

Thromboembolic complication was defined as a thrombus causing a filling defect or completely occlusion of a previouslyvisualized major artery during the procedure. Once embolization was completed, a microcatheter (Rebar - 18, ev3) was advanced across the thrombus, performing superselective angiography beyond the occlusion, confirming correct positioning. A stent retriever device (Solitaire" $4 \mathrm{x} 15 \mathrm{~mm}$ or $4 \mathrm{x} 20 \mathrm{~mm}$, ev3) was deployed a few millimeters distal to the clot and kept opened for five minutes. The microcatheter and the stent retriever were withdrawn under negative pressure applied on the guide catheter, using manual aspiration. Angiographic revascularization was classified using the Modified Treatment in Cerebral Ischemia (mTICI) scale ${ }^{11}$. All patients underwent immediate angiographic control and CT scan or MRI within 24 hours after the procedure. At the end of the catheterization, endovenous heparin administration was interrupted but not antagonized. All patients were transferred to the intensive care unit, and low molecular weight heparin was maintained in prophylactic doses, without reaching anticoagulation. The outcome was evaluated immediately and at a three-month clinical follow-up with telephone assessment of late functional impairment using a validated modified Rankin Scale (mRS) ${ }^{12}$. The last consultation was held between 18 and 67 months.

Our institution follows the Brazilian guidelines for acute ischemic stroke treatment ${ }^{13}$ and the guidelines for the management of patients with unruptured intracranial aneurysms from the American Heart Association/American Stroke Association. ${ }^{14}$

\section{RESULTS}

Ten consecutive patients (eight women) with age ranges from 47 to 80 years (mean age: 56 years) were managed with a stent retriever. Four patients had acute subarachnoid hemorrhage, three were treated during the acute stage and one was treated four months after the hemorrhage. Six had embolization with an unruptured aneurysm. At the onset of the embolization procedure, none of the patients had focal neurologic deficits; the Glasgow Coma Scale was 15 in all but one, who scored 13. Four patients used preoperative antiplatelet therapy due to the elective indication for stent placement. There was only one case of hemorrhagic transformation, resulting in the worst clinical outcome. Three patients had been treated for another cerebral aneurysm several years before (two unruptured, which were embolized and one ruptured, which was clipped). Nine patients were treated for the first time, while one underwent a second endovascular procedure due to recanalization. In all cases but one, the thrombus was noted at the end of the procedure. Patient demographics are summarized in Table 1.

Four treated aneurysms were located in the anterior communicating artery, two in the basilar artery tip, two in the posterior communicating artery, one at the cavernous segment and one at the ophthalmic segment of the internal carotid artery. The aneurysms had an average size of 12.2 $\mathrm{mm}$ (3-variacao de tamanho: entre 3 e $30 \mathrm{~mm}$ ), most of them $(80 \%)$ being wide neck aneurysms. One unruptured basilar artery aneurysm was partially thrombosed. The aneurysm and thrombus locations are shown in Table 2.

Four patients received intravenous rTPA and one received ReoPro, all without opening the vessel.

The average duration of the procedure (time from puncture to final embolization and visualization of the complication) was 109.55 (22169) minutes. One thrombus was localized in the left anterior cerebral artery; two in the right middle cerebral artery and five in the left middle cerebral artery; one in the left posterior cerebral artery; and one in the right posterior cerebral artery. Five patients received rTPA ( four intra-arterially and one intravenously), while another received intra-arterial ReoPro before the use of the stent retriever. The Solitaire 4 x 15 stent was used in five patients and the $4 \times 20$ in five patients. The mean duration of occlusion was 43.8 (15-95) minutes. The average number of passages of the stent retriever was $3.9(1-7)$ times. Coil cast dislodgement was not seen, and there were no additional complications or mortalities related to the procedure.

Retrieval was successful in eight patients, with a control angiogram showing complete recanalization in five patients (mTICI 3). Good recanalization, mTICI 2b, was achieved in three patients, and poor recanalization, mTICI $2 \mathrm{a}$, was achieved in two patients. In the early postoperative period, five patients had a normal neurological examination and maintained a mRS 0 (Figure 1). Three patients showed initial focal deficits, with partial recovery at discharge. Reperfusion was late/insufficient in two patients, with ischemia seen on the postoperative CT scan. 
Table 1. Patient characteristics.

\begin{tabular}{|c|c|c|c|c|c|c|c|c|c|c|}
\hline Patient & Age $(y) /$ Sex & Diagnosis & $\begin{array}{l}\text { Aneurysm } \\
\text { Location }\end{array}$ & $\begin{array}{l}\text { Size } \\
(\mathrm{mm})\end{array}$ & Neck & Ictus & $\mathrm{HH}$ & FS & $\begin{array}{l}\text { Remodeling } \\
\text { Balloon }\end{array}$ & $\begin{array}{c}\text { Stent } \\
\text { Assistance }\end{array}$ \\
\hline 1 & $59 / F$ & Multiple aneurysms & LPComm & 13 & Wide & NA & NA & 1 & $4 \times 15$ & No \\
\hline 2 & $60 / \mathrm{M}$ & Multiple aneurysms & AComm & 8 & Wide & NA & NA & 1 & $4 \times 7$ & No \\
\hline 3 & $50 / F$ & $\begin{array}{l}\text { Subarachnoid } \\
\text { aneurysm }\end{array}$ & Basilar tip & 10 & Wide & D4 & 1 & 2 & $4 \times 20$ & $6 \times 20$ \\
\hline 4 & $54 / \mathrm{M}$ & Headache & Basilar tip & 13 & Wide & NA & NA & 1 & No & $4 \times 20 ; 4 \times 15$ \\
\hline 5 & $48 / F$ & Multiple aneurysms & $\begin{array}{l}\text { LOphthalmic } \\
\text { ICA }\end{array}$ & 25 & Wide & NA & NA & 1 & No & Flow diverter \\
\hline 6 & $57 / F$ & $\begin{array}{l}\text { Subarachnoid } \\
\text { aneurysm }\end{array}$ & AComm & 7 & Small & D3 & 3 & 4 & $4 \times 7$ & No \\
\hline 7 & $80 / F$ & Ophthalmoparesis & $\begin{array}{l}\text { R Cavernous } \\
\text { ICA }\end{array}$ & 30 & Wide & NA & NA & 1 & No & Flow diverter \\
\hline 8 & $47 / F$ & $\begin{array}{l}\text { Subarachnoid } \\
\text { aneurysm }\end{array}$ & LPComm & 3 & Small & $\begin{array}{c}4 \\
\text { months }\end{array}$ & 1 & 2 & No & No \\
\hline 9 & $50 / F$ & Headache & AComm & 10 & Wide & NA & NA & 1 & No & $4 \times 20$ \\
\hline 10 & $61 / F$ & $\begin{array}{l}\text { Subarachnoid } \\
\text { aneurysm }\end{array}$ & AComm & 3 & Wide & D2 & 2 & 3 & $4 \times 7$ & No \\
\hline
\end{tabular}

AComm: Anterior communicating artery; F: female; FS: Fisher scale; HH: Hunt-Hess scale; ICA: internal carotid artery; L: Left; M: male; F: female; NA; Not Applicable; PComm: Posterior communicating artery; R: Right; y: years.

One of these patients, with a basilar artery aneurysm, had an intrastent thrombosis and evolved with the embolus migrating forward to the P2 segment of the right posterior cerebral artery after stent retrieval (Figure 2). Although an embolectomy was performed, he presented with right homonymous hemianopia and maintained a mRS of 3. Unfortunately, one patient suffered a left middle cerebral artery stroke with hemorrhagic transformation and underwent a decompressive craniectomy, but became bedridden and dependent, with a mRS 5 . The average mRS in this series was initially $1.8(0,0,3,0,5,4,3,3,0,0)$ and after three months was $1.1(0,0,2,0,4,3,1,1,0,0)$, achieving $80 \%$ long-term good neurologic outcomes (between 18 and 67 months). Six patients could return to their previous occupation, two retired due to their illness and two were already retired due to their age.

\section{DISCUSSION}

The aim of the coil placement is to induce thrombosis into the aneurysmal sac. Thrombus formation can occur inside the coil mass and either migrate to cause a distal embolic cerebral infarct or spread during the placement of the coil ${ }^{6}$. Possible explanations of this prothrombotic state include intimal insults due do catheter trauma to the parent vessel wall ${ }^{3,6}$, although no arterial dissection was noted in this series, or the presence of foreign bodies such as catheters and coils within the vascular system that could activate platelet aggregation mechanism ${ }^{3}$. The thrombus formation can also occur inside the guiding catheter and microcatheter.

Thromboembolic risks vary due to several factors, such as patient conditions, time of procedure, aneurysm size and neck, conditions of the surgery and treatment options ${ }^{3}$. The use of remodeling techniques or stents may reduce coil displacement, but may also increase the incidence of thromboembolic events ${ }^{15,16}$. Likewise, flow diverters also have a greater propensity for internal thrombosis due to their metallic surface $^{3}$. The thromboembolism can be diagnosed during coil deposition, at the end of the procedure, or a few hours after embolization $^{6}$. Immediate postoperative panoramic control angiography is strongly recommended by the authors, as early recognition, fast and effective treatment is crucial to reducing the morbidity and mortality rate ${ }^{6}$.

With the evolved understanding of anticoagulation and antiplatelet therapy, in addition to the development of new devices, drugs and customized protocols, the incidence of thromboembolic complications has significantly decreased ${ }^{8}$. Antiplatelets have been used to prevent stent thrombosis, but an insufficient response can occur as a result of drug interaction or resistance, which could occur in up to $33 \%$ of patients using clopidogrel and in $4.2 \%$ using aspirin. Indeed, ticagrelor was an effective alternative therapy for these patients ${ }^{3,17}$. Anticoagulants are another class of drug that has the potential to reduce thromboembolic complications, but there is no consensus in the literature for heparin use or its dosage ${ }^{3}$. Glycoprotein IIb/IIIa antagonists have also been used to prevent thrombus formation until a fibrin coating reduces the coil's thrombogenicity ${ }^{2}$ and, in most of cases, we can manage thrombotic complications without intervention using IIb/IIIa inhibitors.

Clearly, intervention is required in the face of any evidence of thromboembolic phenomena related to the coiling $^{2}$. The primary goal of the procedure should be a TICI $2 \mathrm{~b} / 3$ 


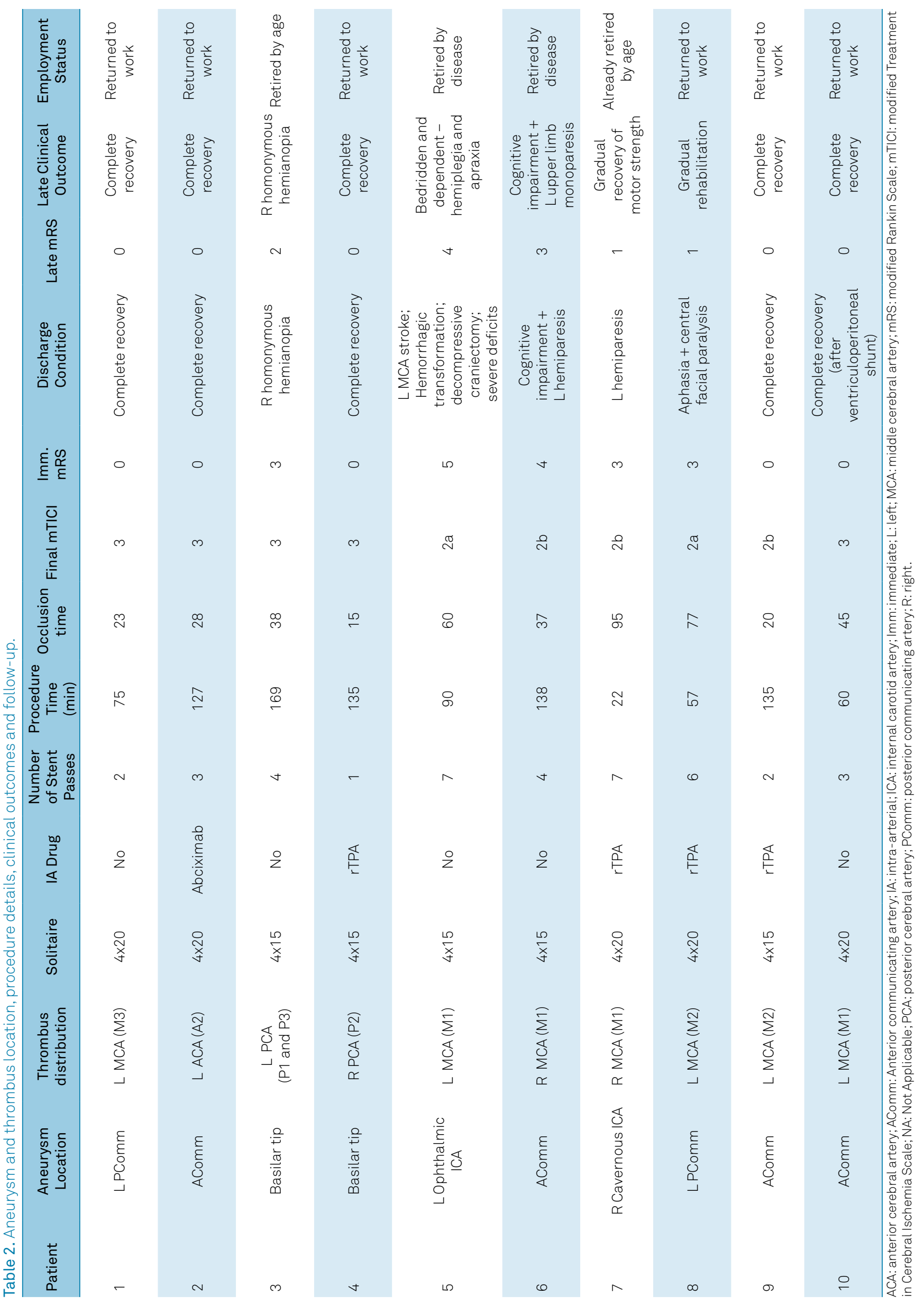



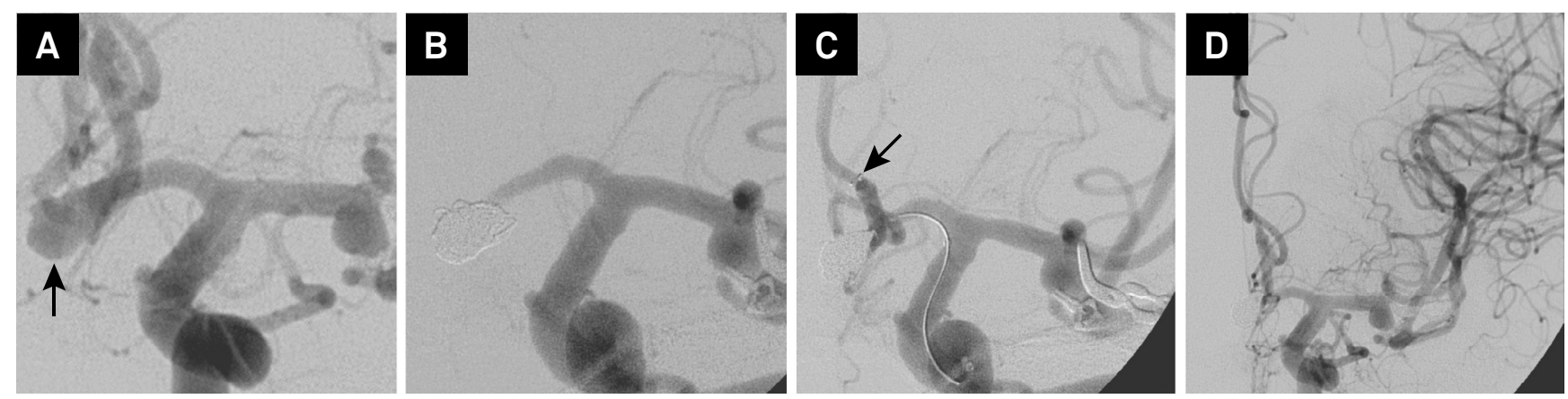

Figure 1. Patient 1 with anterior communicating artery aneurysm after middle cerebral artery aneurysm clipping. (A) Frontal projections shows aneurysm (arrow) filling from left anterior cerebral artery; (B) Treatment with mechanical detachable coils leads to distal anterior cerebral artery occlusion; (C) Deployment of the stent retriever (arrow) restores the blood flow; (D) Immediate control angiogram shows total recanalization. The patient had a good clinical outcome.
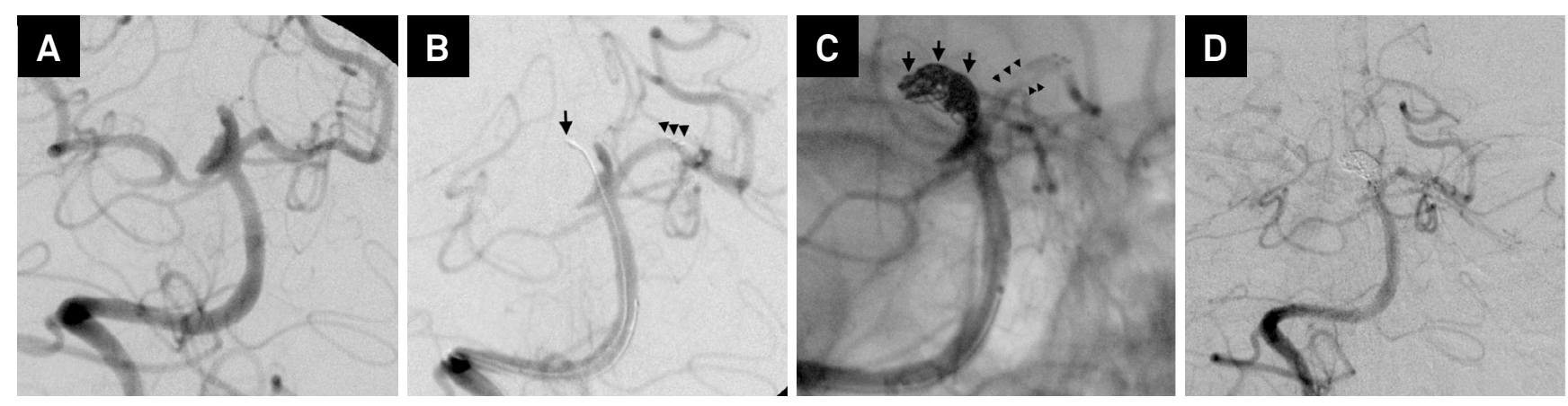

Figure 2. Patient 3 presenting with acute subarachnoid hemorrhage. (A) Frontal angiogram shows a partially thrombosed basilar tip aneurysm; (B) Microcatheter into the thrombus (arrow) and deployment of a stent (arrowheads); (C) After coil placement in the aneurysm (arrows), a thrombus was seen within the stent (arrowheads); (D) Deployment of the stent in the distal left posterior cerebral artery (arrows); (E) Immediate control angiogram shows total recanalization after stent retrieval. The patient remained with homonymous hemianopia.

angiographic recanalization result, with timely restoration of blood flow to avoid brain damage ${ }^{7,10}$. The patient should receive a heparin bolus if not already in use, as well as a loading dose of antiplatelet medication².

The use of new drugs, such as fibrinolytics (rTPA) and platelet inhibitors, decreases the morbidity of the procedure. It has been demonstrated on CT that the use of glycoprotein IIb/IIIa antagonists reduces infarctions by almost $50 \%^{7}$. A meta-analysis evaluating the safety and efficacy of chemical rescue therapy demonstrates significantly greater morbidity with thrombolytic agents than with glycoprotein IIb/IIIa inhibitors? ${ }^{7}$ Tirofiban and eptifibatide result in significantly higher recanalization rates compared with abciximab $^{7}$. The use of chemical thrombolytics achieves up to $80 \%$ of recanalization ${ }^{18}$, but carries the risk of provoking a pharmacological chain reaction resulting in uncontrollable hemorrhage, especially in patients who were premedicated with clopidogrel ${ }^{8}$. Although the clinical outcome has improved with these drugs, in a meta-analysis, Brinjikji et al. ${ }^{7}$ found an average hemorrhage rate of $10 \%$ and mortality rate of up to $25 \%$. In our study, rescue therapy with the stent retriever did not show early postoperative hemorrhage or mortality. Of note, in one patient, the origin of the clot was a pre-existing intraneurysmal thrombus, which may not respond to antiplatelet agents.

The introduction of stent retrieval to treat ischemic stroke enables a rapid and reliable extraction of the thrombus $^{2,8}$. It allows an effective encapsulation of the thrombus (Figure 3), restoration of blood flow and potentiation of thrombolytic substances ${ }^{19}$. Furthermore, modern devices permit faster access and easier navigation due to a more flexible profile ${ }^{20}$. Recent prospective trials have shown the clinical benefit of endovascular therapy, providing high-level evidence that has changed the guidelines of acute stroke therapy to recommend endovascular therapy with a stent retriever over intra-arterial fibrinolysis alone as first-line therapy ${ }^{10,19,20,21}$. However, its use during transprocedural thromboembolic events is still not validated, as the passage of the device over the coil mass could displace it and occlude the parent vessel.

Kadziolka et al. ${ }^{8}$ published a case report of successful mechanical thrombectomy using a Separator 3D' (Penumbra, Alameda, CA, USA) stent retriever. The transprocedural use of the Solitaire $\mathrm{AB}^{*}$ device was reported by Zhang et al., who showed two cases of total recanalization but, unfortunately, with postoperative infarcts in both 


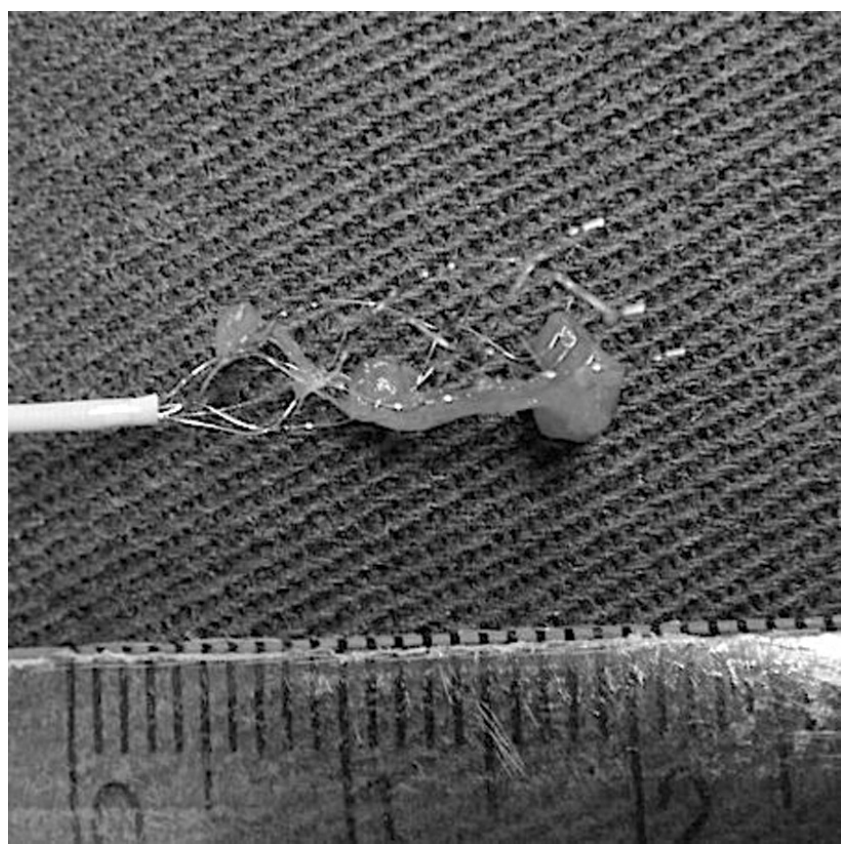

Figure 3. The thrombus is trapped within the stent retriever frame and is removed when the device is withdrawn.

patients9. The stent delivery technique is similar to thrombectomy in stroke and can be used to treat proximal artery occlusions up to the A2 anterior cerebral artery, M2 middle cerebral artery and P2 posterior cerebral artery segments $^{2,3,8}$. Hence, to recanalize vessels less than $2 \mathrm{~mm}$, pharmacologic rescue remains the therapy of choice ${ }^{10}$.

A combined technique of mechanical and chemical thrombolysis may be reasonable in some clinical circumstances, as well as in the current treatment of vasospasm with balloon remodeling and drugs. Deployment of a stent beyond the aneurysm carries the risk of dislodging the coil, particularly in the arterial curves and wide necks of ruptured aneurysms ${ }^{2,8}$. However, in treated patients, the retrieving was uneventful when the stent retriever passed over the coil mass. Another technical limitation is the pulling of the stent retriever through a recently-placed stent, which carries a displacement risk ${ }^{2,8}$. Nevertheless, this risk can be minimized by keeping the initial stent attached to the delivery system, releasing it only after complete embolization of the aneurysm, allowing for retrieval of the stent in the case of intraluminal thrombosis. Although the use of chemical agents is the current indication, the increased effectiveness of recanalization favoring retrievable stents led us to halt the use of drugs as the first option for treating major vessel occlusion.

The stent retriever is also an alternative when thrombolytics are contraindicated, such as after a myocardial infarction within the previous three months ${ }^{22}$. The stent retriever has the potential risk of arterial dissection, muscular spasm and endothelium lesion and this risk increases with the number of passes over the artery. Fortunately, we did not have any complications of this kind in this series. Although the aspiration system has evolved recently, it was not available in our hospital, and there is still no consensus on whether the recanalization rate is superior to the use of the stent retriever.

Our report has the inherent limitations of all retrospective, limited, and single-center patient series. It also does not have a control group. Furthermore, the prior or concomitant use of pharmacologic agents may bias the result as well. However, it is noteworthy that mechanical thrombectomy has achieved recanalization in most patients, compared with the use of drugs alone. Although outcomes have been promising, further prospective controlled trials are necessary to clarify the best techniques for thrombectomy in each location.

In conclusion, mechanical thrombectomy has a valuable role as a safe, simple and effective alternative to reduce the morbidity-mortality rate associated with endovascular treatment of aneurysms ${ }^{2}$, becoming our first choice in the management of proximal intracranial arterial occlusions. The stent retriever should be considered part of the therapeutic armamentarium to minimize the impact of potentially disastrous thromboembolic complications.

\section{References}

1. Viñuela F, Duckwiler G, Mawad M. Guglielmi detachable coil embolization of acute intracranial aneurysm: perioperative anatomical and clinical outcome in 403 patients. 1997. J Neurosurg. 2008 Apr;108(4):832-9. https://doi.org/10.3171/JNS/2008/108/4/0832

2. Leslie-Mazwi TM, Heddier M, Nordmeyer H, Stauder M, Velasco A, Mosimann PJ et al. Stent retriever use for retrieval of displaced microcoils: a consecutive case series. AJNR Am J Neuroradiol. 2013 Oct;34(10):1996-9. https://doi.org/10.3174/ajnr.A3552

3. Bracard S, Barbier C, Derelle AL, Anxionnat R. Endovascular treatment of aneurisms: pre, intra and post operative management. Eur J Radiol. 2013 Oct;82(10):1633-7. https://doi.org/10.1016/j.ejrad.2013.02.012

4. Park HK, Horowitz M, Jungreis C, Genevro J, Koebbe C, Levy E et al. Periprocedural morbidity and mortality associated with endovascular treatment of intracranial aneurysms. AJNR Am J Neuroradiol. 2005 Mar;26(3):506-14.
5. Zheng Y, Liu Y, Leng B, Xu F, Tian Y. Periprocedural complications associated with endovascular treatment of intracranial aneurysms in 1764 cases. J Neurointerv Surg. 2016 Feb;8(2):152-7. https://doi.org/10.1136/neurintsurg-2014-011459

6. Koebbe CJ, Horowitz MB, Levy El, Dutton K, Jungries CC, Purdy PD. Intraarterial thrombolysis for thromboemboli associated with endovascular aneurysm coiling. Report of five cases. Interv Neuroradiol. 2002 Jun;8(2):151-8. https://doi.org/10.1177/159101990200800207

7. Brinjikji W, Morales-Valero SF, Murad MH, Cloft HJ, Kallmes DF. Rescue treatment of thromboembolic complications during endovascular treatment of cerebral aneurysms: a meta-analysis. AJNR Am J Neuroradiol. 2015 Jan;36(1):121-5. https://doi.org/10.3174/ajnr.A4066

8. Kadziolka K, Soize S, Pierot L. Mechanical thrombectomy “as a rescue treatment" of thromboembolic complications during endovascular treatment of intracranial aneurysms. J Neuroradiol. 2013 Dec;40(5):360-3. https://doi.org/10.1016/j.neurad.2013.08.002 
9. Zhang X, Guo Z, Xu R, Sun X, Li Y. Mechanical thrombectomy in two patients using the Solitaire AB device in cerebral aneurysms during endovascular coil embolisation. J Clin Neurosci. 2012 Dec;19(12):1736-8. https://doi.org/10.1016/j.jocn.2012.01.035

10. Powers WJ, Derdeyn CP, Biller J, Coffey CS, Hoh BL, Jauch ED et al. 2015 AHA/ASA Focused Update of the 2013 Guidelines for the early management of patients with acute ischemic stroke regarding endovascular treatment. Stroke. 2015;46(10):3020-35. https://doi.org/10.1161/STR.0000000000000074

11. Zaidat OO, Yoo AJ, Khatri P, Tomsick TA, Kummer R, Saver JL et al. Recommendations on angiographic revascularization grading standards for acute ischemic stroke: a consensus statement. Stroke. 2013 Sep;44(9):2650-63. https://doi.org/10.1161/STROKEAHA.113.001972

12. Baggio JA, Santos-Pontelli TE, Cougo-Pinto PT, Camilo M, Silva NF, Antunes P et al. Validation of a structured interview for telephone assessment of the modified Rankin Scale in Brazilian stroke patients. Cerebrovasc Dis. 2014;38(4):297-301. https://doi.org/10.1159/000367646

13. Ministério da Saúde (BR). Secretaria de Atenção à Saúde. Departamento de Atenção Especializada. Manual de rotinas para atenção ao AVC. Brasília, DF: Ministério da Saúde; 2013.

14. Thompson BG, Brown RD Jr, Amin-Hanjani S, Broderick JP, Cockroft KM, Connolly ES Jr et al. Guidelines for the management of patients with unruptured intracranial aneurysms: a guideline for healthcare professionals from the American Heart Association/ American Stroke Association. Stroke. 2015 Aug;46(8):2368-400. https://doi.org/10.1161/STR.0000000000000070

15. Rooij WJ, Sluzewski M, Beute GN, Nijssen PC. Procedural complications of coiling of ruptured intracranial aneurysms: incidence and risk factors in a consecutive series of 681 patients. AJNR Am J Neuroradiol. 2006 Aug;27(7):1498-501.
16. Shapiro M, Becske T, Sahlein D, Babb J, Nelson PK. Stent-supported aneurysm coiling: a literature survey of treatment and follow-up. AJNR Am J Neuroradiol. 2012 Jan;33(1):159-63. https://doi.org/10.3174/ajnr.A2719

17. Hanel RA, Taussky P, Dixon T, Miller DA, Sapin M, Nordeen JD et al. Safety and efficacy of ticagrelor for neuroendovascular procedures. A single center initial experience. J Neurointerv Surg. 2014 May;6(4):320-2. https://doi.org/10.1136/neurintsurg-2013-010699

18. Bruening R, Mueller-Schunk S, Morhard D, Seelos KC, Brueckmann $\mathrm{H}$, Schmid-Elsaesser R et al. Intraprocedural thrombus formation during coil placement in ruptured intracranial aneurysms: treatment with systemic application of the glycoprotein IIb/IIla antagonist tirofiban. AJNR Am J Neuroradiol. 2006 Jun-Jul;27(6):1326-31.

19. Ferri CP, Buehler A, Flato UA, Puglia Junior P, Fernandes JG. Endovascular thrombectomy for the treatment of acute ischemic stroke. Arq Neuropsiquiatr. 2016 Jan;74(1):67-74. https://doi.org/10.1590/0004-282X20150182

20. Evaristo EF. Endovascular thrombectomy in acute ischemic stroke: a major breakthrough and a big challenge for Brazil. Arq Neuropsiquiatr. 2016 Jan;74(1):1-2. https://doi.org/10.1590/0004-282X20150209

21. Lucena AF, Castro-Afonso LH, Monsignore LM, Nakiri GS, Fábio SR, Pontes Neto $\mathrm{O}$ et al. Carotid artery stenting in the context of endovascular treatment of acute ischemic stroke. Arq Neuropsiquiatr. 2016 Mar;74(3):212-8. https://doi.org/10.1590/0004-282X20150213

22. Kuster GW, Baruzzi AC, Pacheco EP, Domingues RB, Pieruccetti $M$, Giacon LM et al. Early reperfusion therapy in acute ischemic stroke after recent myocardial infarction. Arq Neuropsiquiatr. 2016 Aug;74(8):690-1. https://doi.org/10.1590/0004-282X20160099 